Supporting Information for

\title{
Anisotropic Diffusion in Face-Centered Cubic Opals
}

Michael R. Newton, Kathleen A. Morey, Yanhui Zhang, Ryan J. Snow, ' Mohit Diwekar,' Jing Shi, ${ }^{*}$ and Henry S. White*

Departments of Chemistry and Physics

University of Utah, Salt Lake City, UT 84112

The following two pages show the concentration and flux distributions for diffusion normal to the (100) and (110) surfaces for an opal with $N=3$. The open-spherical regions correspond to spherical particles. These figures are analogous to Figure 5 in the text. 
(A) 100 Conc.

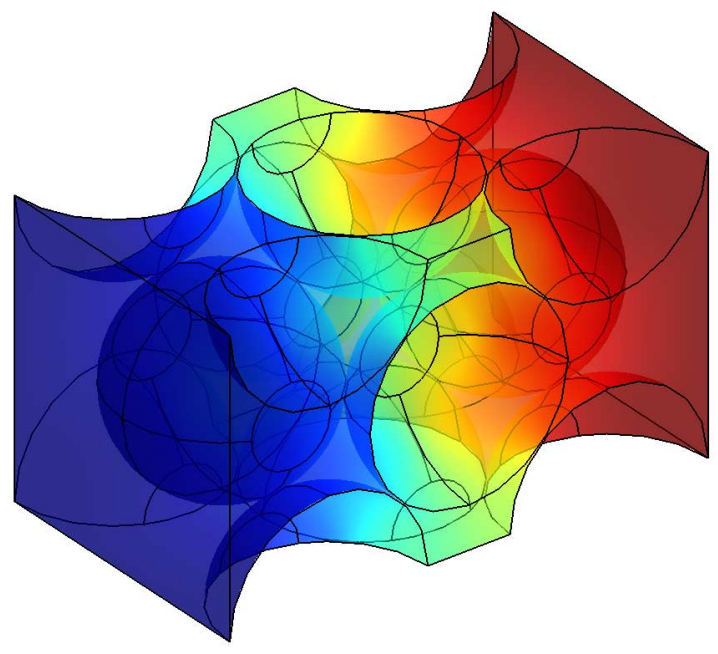

(B) 100 FLux

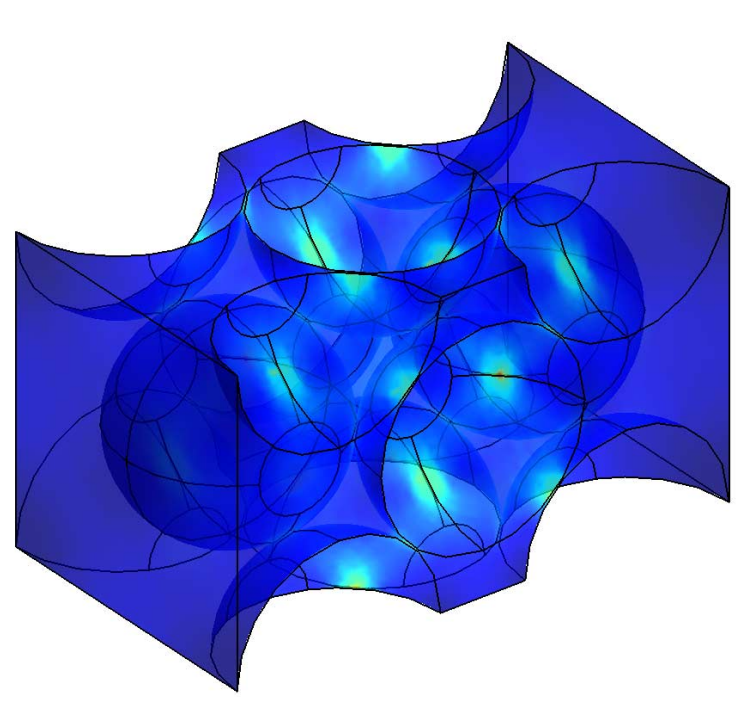

$\mathrm{mM}$

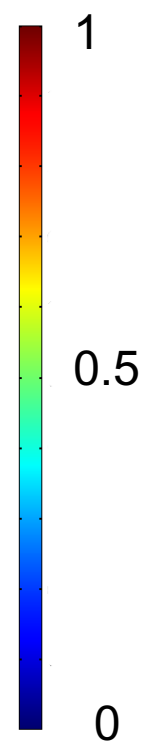

$\mathrm{Mol} / \mathrm{cm}^{2} \mathrm{~s}$

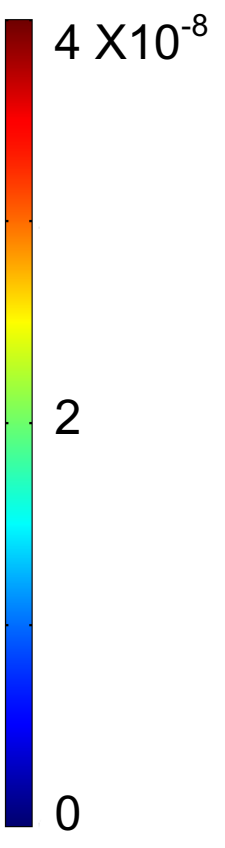


$\mathrm{mM}$

(A) 110 Conc.
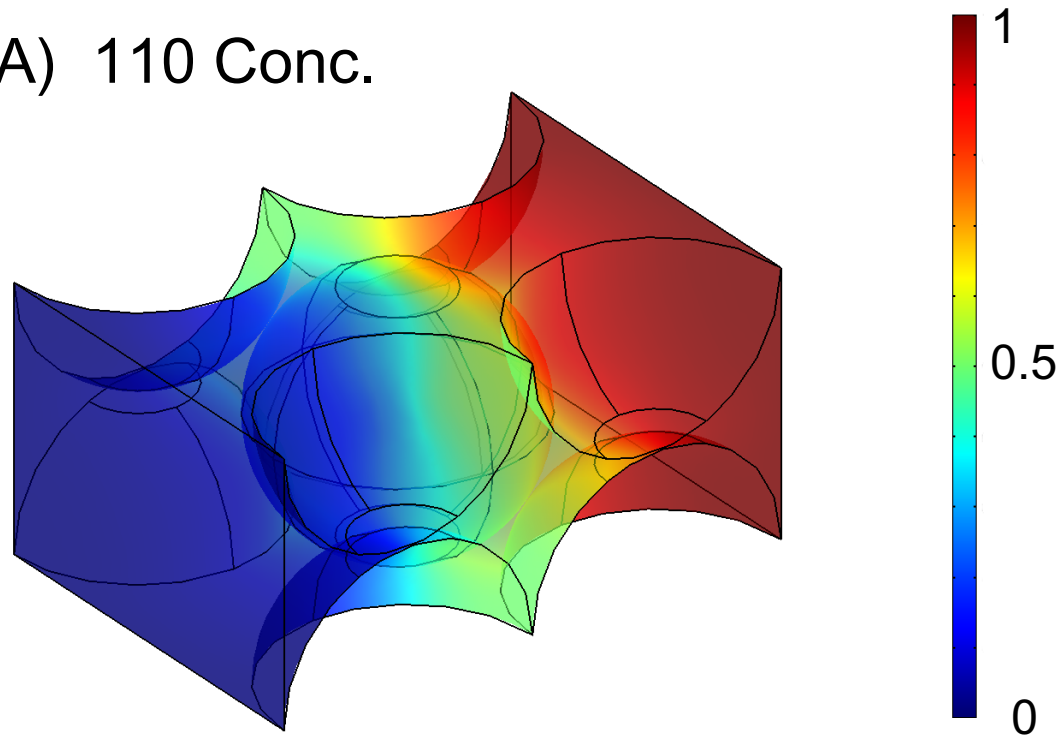

(B) 110 Flux

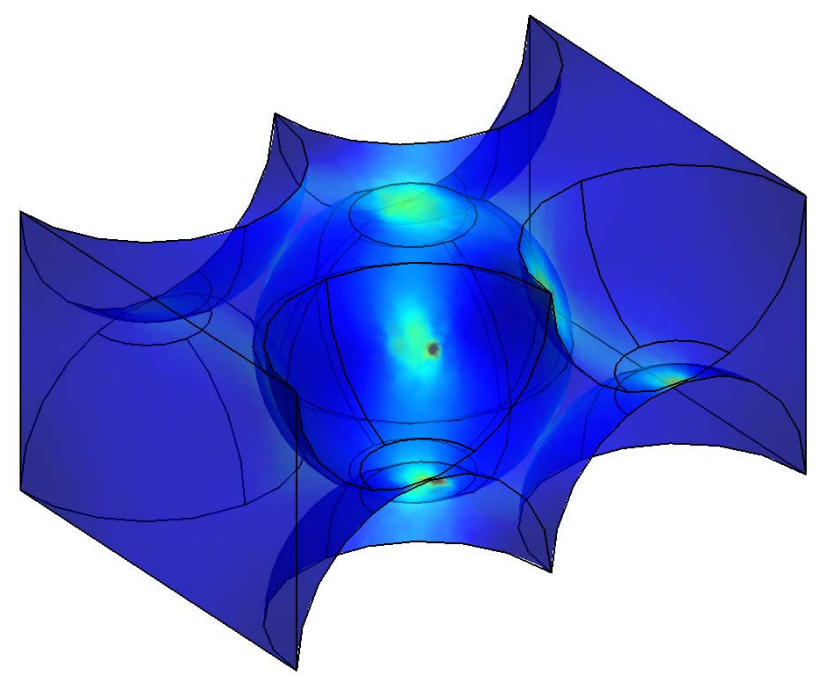

$\mathrm{Mol} / \mathrm{cm}^{2} \mathrm{~s}$

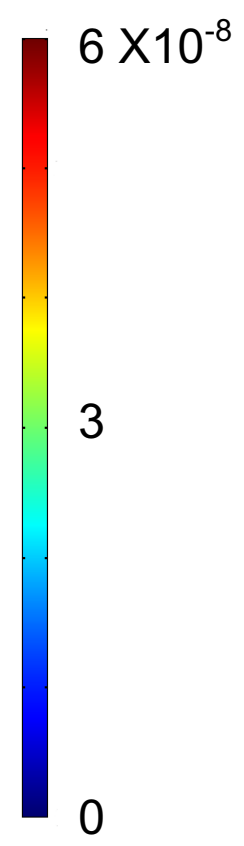

